\title{
ANALISIS LOAD FACTOR PERJALANAN KRL COMMUTER LINE BERDASARKAN TITIK JENUH LINTAS ( STUDI KASUS LINTAS BOGOR - MANGGARAI )
}

\author{
Aditya Wahyu Erlangga ${ }^{1}$, email: aditya@ppi.ac.id \\ Dedik Tri Istiantara ${ }^{2}$ email: dedik@ppi.ac.id \\ Ikhsan Nugroho ${ }^{3}$, email: nugrohoikhsan88@gmail.com \\ ${ }^{1}$ Teknologi Bangunan dan Jalur Perkeretaapian, ${ }^{2,3}$ Manajemen Transportasi Perkeretaapian, \\ Politeknik Perkeretaapian Indonesia Madiun
}

\begin{abstract}
ABSTRAK
Wilayah yang memiliki frekuensi penduduk terpadat di Indonesia yaitu wilayah Jabodetabek, sering terjadi kemacetan di wilayah Jabodetabek. PT KCI memberikan pelayanan perjalanan KRL di wilayah Jakarta, Bogor, Depok, Tangerang, Bekasi, Cikarang, Maja, Rangkasbitung. Salah satu lintas terpadat yaitu lintas Bogor - Manggarai karena banyaknya pekerja dari Bogor menuju Jakarta menggunakan transportasi KRL. Sarana KRL yang melintas pada lintas tersebut dirasa kurang karena masih banyak penumpang yang belum terangkut saat jam sibuk dan terjadi kepadatan penumpang di dalam rangkaian KRL. Maka perlu adanya penelitian mengenai load factor perjalanan KRL lintas Manggarai - Bogor KRL guna mengangkut penumpang secara aman dan nyaman. Analisis bertujuan mengetahui load factor dan titik jenuh lintas perjalanan KRL lintas Bogor - Manggarai. Analisis load factor berdasarkan titik jenuh lintas dilakukan dengan cara perhitungan headway, kapasitas lintas, kapasitas angkut lintas, dan hasil bagi dari jumlah penumpang dengan kapasitas angkut lintas. Hasil penelitian menyatakan saat peak hour perjalanan sekarang jenuh $-3,44$ tahun load factor sebesar $153 \%$, perjalanan maksimal berdasarkan perjalanan awal jenuh $-1,15$ tahun dan load factor sebesar 115\%, perjalanan stamformasi 12 menunjukkan angka kejenuhan 0,58 tahun dan load factor sebesar 93\%. Saat off peak hour lintas Bogor - Manggarai perjalanan saat ini menunjukkan angka kejenuhan 2,71 tahun dan load factor sebesar $72 \%$, perjalanan maksimal berdasarkan perjalanan awal, menunjukkan angka 5,1 tahun dan load factor sebesar 53\%, perjalanan stamformasi 12 menunjukkan angka kejenuhan 6,76 tahun dan load factor $43 \%$.
\end{abstract}

Kata kunci : titik jenuh, peak hour, off peak hour, load factor

\section{ABSTRACT}

The area that has the most populous frequency in Indonesia, namely the Jabodetabek area, congestion often occurs in the Jabodetabek area. PT KCI provides KRL travel services in the Jakarta, Bogor, Depok, Tangerang, Bekasi, Cikarang, Maja, Rangkasbitung areas. One of the busiest routes is the Bogor Manggarai route because many workers from Bogor to Jakarta use KRL transportation. The KRL facilities that pass on this route are deemed inadequate because there are still many passengers who have not been transported during peak hours and there is a density of passengers in the KRL series. So there is a need for research on the load factor for KRL trips between Manggarai - Bogor KRL in order to transport passengers safely and comfortably. The analysis aims to determine the load factor and saturation point of the KRL trip between Bogor - Manggarai. Load factor analysis based on cross saturation point is carried out by calculating the headway, traffic capacity, cross-carrying capacity, and the quotient of the number of passengers with cross-carrying capacity. The results of the study stated that when the peak hour of travel is now saturated -3.44 years, the load factor is $153 \%$, the maximum trip is based on the initial journey of being saturated -1.15 years and the load factor is $115 \%$, the journey of stamformasi 12 shows a saturation rate of 0.58 years and load a factor of 93\%. During the off-peak hour crossing the Bogor-Manggarai route, the current trip shows a saturation rate of 2.71 years and a load factor of $72 \%$, the maximum trip is based on the initial trip, shows a number of 5.1 years and a load factor of 53\%, a trip of 12 shows a saturation rate 6.76 years and a load factor of $43 \%$.

Key words: saturation point, peak hour, off peak hour, load factor 


\section{LATAR BELAKANG}

Indonesia merupakan salah satu negara yang memiliki tingkat kepadatan penduduk yang tinggi di dunia. Transportasi sebagai alat penunjang dan penggerak dinamika pembangunan, dikarenakan transportasi juga katalisator dalam meningkatkan pertumbuhan ekonomi dan perkembangan wilayah (Timboeleng A. James, Kaseke H. Oscar, 2015). Wilayah yang memiliki frekuensi penduduk terpadat di Indonesia yaitu wilayah Jabodetabek, sering terjadi kemacetan di wilayah Jabodetabek. Kemacetan merupakan masalah yang timbul akibat pertumbuhan dan kepadatan penduduk (Hoeve, 1990) sehingga arus kendaraan bergerak sangat lambat. PT KCI memberikan pelayanan perjalanan KRL di wilayah Jakarta, Bogor, Depok, Tangerang, Bekasi, Cikarang, Maja, Rangkasbitung. Salah satu lintas terpadat yaitu lintas Bogor Manggarai karena banyaknya pekerja dari Bogor menuju Jakarta menggunakan transportasi KRL. Sarana KRL yang melintas pada lintas tersebut dirasa kurang karena masih banyak penumpang yang belum terangkut saat jam sibuk dan terjadi kepadatan penumpang di dalam rangkaian KRL. Maka perlu adanya penelitian mengenai load factor perjalanan KRL lintas Manggarai - Bogor KRL guna mengangkut penumpang secara aman dan nyaman. Analisis bertujuan mengetahui pertumbuhan jumlah penumpang Lintas Bogor - Manggarai, mengetahui waktu terjadinya titik jenuh lintas Bogor Manggarai, mengetahui load factor lintas Bogor - Manggarai berdasarkan titik jenuh lintas.

\section{METODE PENELITIAN}

Penelitian ini dimaksudkan untuk mengetahui load factor perjalanan KRL lintas Bogor -
Manggarai berdasarkan titik jenuh lintas, sehingga perusahaan dapat mengetahui kapan lintas tersebut mencapai puncak untuk mengangkut penumpang KRL dan dapat menyiapkan rencana kedepan mulai dini. Oleh karena itu, untuk mendapatkan hasil maksimal dalam penelitian dilakukan tahapan sebagai berikut.

1. Studi literatur mengenai kapasitas lintas dan faktor-faktor yang mempengaruhinya.

2. Pengumpulan data sekunder berupa dari Grafik Perjalanan Kereta Api (Gapeka), Tabel Kereta Api (O.100), Tabel Dinasan Sarana KRL (O.18), Data penumpang KRL, yang diperoleh dari PT.KCI .

3. Pengumpulan data primer yaitu berupa observasi lapangan untuk mengetahui kondisi lintas Bogor - Manggarai serta menganalisis perjalanan KRL.

4. Analisis data menggunakan analisis stastistik sederhana untuk menganalisis data yang didapat dari hasil pengumpulan data sekunder dan data primer.

\section{HASIL PENELITIAN DAN PEMBAHASAN}

Pertumbuhan penumpang yang tinggi menggunakan kereta rel listrik di lintas perkotaan semakin meningkat dari tahun ketahun. Beberapa keunggulan kereta rel listrik yaitu ketepatan waktu yang andal, kenyamanan dan keamanan perjalanan kereta rel listrik lebih efektif dan efisien dibandingkan dengan transportasi umum moda angkutan darat. Berikut adalah data jumlah penumpang perjalanan kereta rel listrik di PT. Kereta Commuter Indonesia pada bulan Agustus 2018 - Desember 2018 :

Tabel 1. Jumlah Penumpang

\begin{tabular}{|c|c|c|c|c|c|c|}
\hline \multirow{2}{*}{ No } & \multirow{2}{*}{ Stasiun } & \multicolumn{5}{|c|}{ Realisasi } \\
\cline { 3 - 7 } & & Agu-18 & Sep-18 & Okt-18 & Nov-18 & Des-18 \\
\hline 1 & Manggarai & 618.098 & 626.628 & 666.327 & 639.306 & 630.774 \\
\hline 2 & Tebet & 921.657 & 904.460 & 973.984 & 926.010 & 919.301 \\
\hline 3 & Cawang & 442.471 & 432.345 & 476.660 & 451.127 & 427.845 \\
\hline
\end{tabular}




\begin{tabular}{|c|c|c|c|c|c|c|}
\hline 4 & Duren Kalibata & 616.882 & 614.364 & 653.266 & 619.034 & 632.991 \\
\hline 5 & $\begin{array}{c}\text { Pasar Minggu } \\
\text { Baru }\end{array}$ & 141.574 & 138.103 & 146.815 & 139.358 & 142.562 \\
\hline 6 & Pasar Minggu & 612.974 & 612.678 & 652.129 & 623.824 & 657.907 \\
\hline 7 & Tanjung Barat & 380.754 & 386.124 & 415.459 & 394.282 & 402.435 \\
\hline 8 & Lenteng Agung & 438.729 & 440.907 & 460.777 & 436.478 & 457.289 \\
\hline 9 & Univ. Pancasila & 200.164 & 232.150 & 251.422 & 233.742 & 216.297 \\
\hline 10 & $\begin{array}{c}\text { Univ. } \\
\text { Indonesia }\end{array}$ & 273.673 & 343.834 & 360.540 & 335.507 & 305.506 \\
\hline 11 & Pondok Cina & 655.544 & 673.805 & 718.984 & 669.353 & 646.158 \\
\hline 12 & Depok Baru & 1.035 .562 & 1.028 .423 & 1.076 .786 & 1.027 .142 & 1.098 .201 \\
\hline 13 & Depok & 765.649 & 744.693 & 809.758 & 761.264 & 770.248 \\
\hline 14 & Citayam & 1.011 .982 & 996.134 & 1.068 .428 & 1.031 .588 & 1.091 .079 \\
\hline 15 & Bojong Gede & 1.047 .680 & 1.030 .587 & 1.104 .793 & 1.052 .339 & 1.096 .932 \\
\hline 16 & Cilebut & 567.494 & 556.794 & 602.813 & 574.747 & 583.749 \\
\hline 17 & Bogor & 1.436 .082 & 1.416 .109 & 1.472 .681 & 1.428 .206 & 1.559 .426 \\
\hline & TOTAL & $\mathbf{1 1 . 1 6 6 . 9 6 9}$ & $\mathbf{1 1 . 1 7 8 . 1 3 8}$ & $\mathbf{1 1 . 9 1 1 . 6 2 2}$ & $\mathbf{1 1 . 3 4 3 . 3 0 7}$ & $\mathbf{1 1 . 6 3 8 . 7 0 0}$ \\
\hline & Total 5 bulan & & & & & $\mathbf{5 7 . 2 3 8 . 7 3 6}$ \\
\hline
\end{tabular}

Dari tabel data jumlah penumpang di atas dapat juga dihitung tingkat pertumbuhan penumpang dari bulan Agustus - Desember dengan cara sebagai berikut :

Rumus Tingkat Pertumbuhan Penumpang

$\mathrm{r}=-1+{ }^{\mathrm{n}} \sqrt{\mathrm{n} / \mathrm{Vo}}$

Keterangan :

$\mathrm{Vn}=$ Jumlah penumpang pada waktu yang akan datang

Vo = Jumlah penumpang pada saat ini

$\mathrm{r} \quad=$ Tingkat pertumbuhan

$\mathrm{n} \quad=$ waktu dalam bulan/tahun

Pertumbuhan Lintas Bogor - Manggarai

$\mathrm{V}_{0}=11.166 .969$

$\mathrm{Vn}=11.638 .700$

$\mathrm{n}=4$

\section{$r=-1+\sqrt[4]{\mathbf{1 1 . 6 3 8 . 7 0 0 / 1 1 . 1 6 6 . 9 6 9}}$ \\ $r=0,01034$}

\section{Headway Lintas Bogor - Manggarai}

System persinyalan pada lintas Bogor Manggarai menggunakan jenis persinyalan blok otomatik terbuka dengan 2 aspek hijau maka rumus yang digunakan untuk mencari Headway pada lintas Bogor - Manggarai yaitu

$H=\frac{180 \times B+60}{V}+0,25$

Keterangan :

$\mathrm{H}=$ Headway

$\mathrm{B}=$ Jarak antara petak blok

Stasiun a ke stasiun b

$180=$ Jarak setelah pelayanan blok sinyal

$\mathrm{V}=$ Kecepatan

$0,25=$ Waktu Pelayanan blok dan sinyal

Tabel 2. Headway lintas Bogor - Manggarai

\begin{tabular}{|c|c|c|c|}
\hline Lintas Stasiun & $\begin{array}{c}\text { Jarak Blok } \\
\text { Terjauh }(\mathrm{km})\end{array}$ & $\begin{array}{c}\text { Kecepatan } \\
(\mathrm{km} / \mathrm{jam})\end{array}$ & $\begin{array}{c}\text { Headway } \\
(\mathrm{menit})\end{array}$ \\
\hline Bogor - Cilebut & 1,051 & 62 & 5 \\
\hline Cilebut - Bojong Gede & 1,048 & 62 & 5 \\
\hline Bojong Gede - Citayam & 1,072 & 62 & 5 \\
\hline Citayam - Depok & 1,100 & 62 & 5 \\
\hline Depok - Universitas Indonesia & 1,100 & 62 & 5 \\
\hline Universitas Indonesia - Pasar Minggu & 1,079 & 62 & 5 \\
\hline
\end{tabular}


Pasar Minggu - Manggarai

Dari data diatas dapat diketahui dan disimpulkan bahwa headway pada lintas Bogor - Manggarai adalah sebesar 5 menit.

\section{Analisis Kapasitas Lintas Bogor - Manggarai}

Kapasitas lintas disebut juga sebagai kemampuan suatu lintas untuk menampung perjalanan kereta api yang umumnya dinyatakan dalam 24 jam atau 1440 menit. Akan tetapi, untuk KRL hanya terdiri dari 22 jam atau 1320 menit. Hal ini karena disesuaikan dengan jam operasional KRL. Jam operasional KRL tentu mempertimbangkan demand penumpang. Dari hasil observasi lapangan, maka dapat ditentukan bahwa total jam padat (peak hour) adalah 8 jam sedangkan bukan jam padat (off peak hour) adalah 14 jam. Berikut rumus perhitungan kapasitas lintas Bogor Manggarai

Jalur Ganda Peak Hour

$K=\frac{480}{H} \times 2 \times 0,7$

Jalur Ganda Off Peak Hour

$K=\frac{840}{H} \times 2 \times 0,7$

Keterangan :

$\mathrm{K}=$ Kapasitas Lintas

$\mathrm{H}=$ Headway

2 = Pada jalur ganda yang digunakan KRL perlu dikalikan 2

$\mathrm{F}=$ Faktor pengali setelah dikurangi faktor waktu perawatan dan waktu karena pola operasi $60 \%$ pada jalur tunggal dan $70 \%$ untuk jalur ganda.

Tabel 3. Kapasitas Lintas Bogor - Manggarai

\begin{tabular}{|c|c|c|c|}
\hline \multirow{2}{*}{ Lintas Stasiun } & \multicolumn{3}{|c|}{ Kapasitas Lintas } \\
\cline { 2 - 4 } & Peak Hour & Off Peak Hour & Total \\
\hline Bogor - Cilebut & 134 & 235 & 369 \\
\hline Cilebut - Bojong Gede & 134 & 235 & 369 \\
\hline Bojong Gede - Citayam & 134 & 235 & 369 \\
\hline Citayam - Depok & 134 & 235 & 369 \\
\hline Depok - Universitas Indonesia & 134 & 235 & 369 \\
\hline Universitas Indonesia - Pasar Minggu & 134 & 235 & 369 \\
\hline Pasar Minggu - Manggarai & 134 & 235 & 369 \\
\hline
\end{tabular}

Kapasitas lintas Bogor - Manggarai yaitu saat Peak Hour sebanyak 134 perjalanan dan saat Off Peak Hour sebanyak 235 perjalanan. Sehingga perjalanan KRL sehari yaitu sebanyak 369 perjalanan. Perjalanan ini merupakan perjalanan maksimal KRL lintas Bogor - Manggarai berdasarkan kemampuan sarana dan prasarana lintas tersebut.

\section{Kapasitas Angkut Sarana KRL Seri JR 205}

Lintas Bogor - Manggarai menggunakan seri KRL JR 205 dengan 8, 10, dan 12 rangkaian kereta. Untuk 8 rangkaian dapat mengangkut 1.136 penumpang, 10 rangkaian mengangkut 1.424 penumpang, dan 12 rangkaian mengangkut 1.712 penumpang dalam sekali perjalanan. Jumlah tersebut merupakan jumlah normal atau layak bagi penumpang KRL karena seluruh penumpang mendapatkan tempat duduk dan/atau handgripe.

\section{Kapasitas Angkut Lintas}


Setelah ditentukan bahwa penumpang akan terus mengalami peningkatan maka perlu diperhitungkan kemampuan lintas untuk menampung jumlah penumpang. Berikut adalah tabel kemampuan maksimal lintas untuk menampung penumpang KRL.

Tabel 4. Perjalanan KRL

\begin{tabular}{|c|c|c|c|c|c|c|}
\hline Lintas & \multicolumn{2}{|c|}{ Perjalanan saat ini } & \multicolumn{2}{c|}{$\begin{array}{c}\text { Perjalanan Maksimal } \\
\text { Stamformasi 8,10,12 }\end{array}$} & \multicolumn{2}{c|}{$\begin{array}{c}\text { Perjalanan Maksimal } \\
\text { Stamformasi 12 }\end{array}$} \\
\cline { 2 - 7 } & Peak Hour & $\begin{array}{c}\text { Off Peak } \\
\text { Hour }\end{array}$ & Peak Hour & $\begin{array}{c}\text { Off Peak } \\
\text { Hour }\end{array}$ & Peak Hour & $\begin{array}{c}\text { Off Peak } \\
\text { Hour }\end{array}$ \\
\hline $\begin{array}{c}\text { Bogor - } \\
\text { Manggarai }\end{array}$ & 101 & 175 & 134 & 235 & 134 & 235 \\
\hline
\end{tabular}

Tabel 5. Kapasitas Angkut Lintas

\begin{tabular}{|c|c|c|c|c|c|c|c|c|}
\hline \multirow{3}{*}{ Lintas } & \multicolumn{2}{|c|}{$\begin{array}{c}\text { Jumlah penumpang } \\
\text { bulan Desember }\end{array}$} & \multicolumn{2}{|c|}{\begin{tabular}{c}
\multicolumn{2}{|c|}{ Kapasitas angkut lintas } \\
Perjalanan saat ini
\end{tabular}} & $\begin{array}{c}\text { Kapasitas angkut } \\
\text { lintas Perjalanan } \\
\text { Maksimal } \\
\text { Stamformasi 8,10,12 }\end{array}$ & \multicolumn{2}{c|}{$\begin{array}{c}\text { Kapasitas angkut lintas } \\
\text { Perjalanan Maksimal } \\
\text { Stamformasi } 12\end{array}$} \\
\cline { 2 - 9 } & $\begin{array}{c}\text { Peak } \\
\text { Hour }\end{array}$ & $\begin{array}{c}\text { Off Peak } \\
\text { Hour }\end{array}$ & $\begin{array}{c}\text { Peak } \\
\text { Hour }\end{array}$ & $\begin{array}{c}\text { Off Peak } \\
\text { Hour }\end{array}$ & $\begin{array}{c}\text { Peak } \\
\text { Hour }\end{array}$ & $\begin{array}{c}\text { Off Peak } \\
\text { Hour }\end{array}$ & $\begin{array}{c}\text { Peak } \\
\text { Hour }\end{array}$ & $\begin{array}{c}\text { Off Peak } \\
\text { Hour }\end{array}$ \\
\hline $\begin{array}{c}\text { Bogor- } \\
\text { Manggarai }\end{array}$ & 6.401 .285 & 5.237 .415 & 4.183 .855 & 7.321 .745 & 5.550 .857 & 9.832 .058 & 6.882 .240 & 12.069 .600 \\
\hline
\end{tabular}

Untuk dapat mengetahui waktu terjadinya titik jenuh kapasitas lintas ditinjau dari pertumbuhan jumlah penumpang maka dapat diketahui dengan menggunakan rumus load factor lintas dan laju pertumbuhan sebagai berikut.

$$
\begin{aligned}
& \mathrm{n}={ }^{1+\mathrm{r}} \log \mathrm{Vn}-{ }^{1+\mathrm{r}} \log \mathrm{Vo} . . . \ldots \ldots \ldots \ldots \ldots \ldots \ldots . . . . . . . . \\
& L F=\frac{\text { Jumlah Penumpang }}{\text { Kapasitas Angkut Lintas }} \times 100 \%
\end{aligned}
$$

Tabel 6. Titik Jenuh Lintas dan Load Factor Perjalanan Saat ini

\begin{tabular}{|c|c|c|c|c|c|c|}
\hline Lintas & $\begin{array}{c}\text { Laju } \\
\text { Pertumbuhan } \\
\text { Penumpang } \\
(\mathrm{r})\end{array}$ & $\begin{array}{c}\text { Jumlah } \\
\text { Penumpang } \\
\text { Desember } \\
2018\left(\mathrm{~V}_{0}\right)\end{array}$ & $\begin{array}{c}\text { Kapasitas } \\
\text { Angkut } \\
\text { Lintas } \\
(\text { Vn) }\end{array}$ & $\begin{array}{c}\text { Titik Jenuh } \\
\text { Kapasitas } \\
\text { Lintas } \\
\text { (bulan) }\end{array}$ & $\begin{array}{c}\text { Titik Jenuh } \\
\text { Kapasitas } \\
\text { Lintas } \\
\text { (tahun) }\end{array}$ & $\begin{array}{c}\text { Load } \\
\text { Factor } \\
(\%)\end{array}$ \\
\hline $\begin{array}{c}\text { Bogor - Manggarai Peak } \\
\text { Hour perjalanan saat ini }\end{array}$ & 0,01034 & 6.401 .285 & 4.183 .855 & $-41,34$ & $-3,44$ & 153 \\
\hline $\begin{array}{c}\text { Bogor - Manggarai Off } \\
\text { Peak Hour perjalanan saat } \\
\text { ini }\end{array}$ & 0,01034 & 5.237 .415 & 7.321 .745 & 32,56 & 2,71 & 72 \\
\hline $\begin{array}{c}\text { Bogor - Manggarai Peak } \\
\text { Hour perjalanan maksimal } \\
\text { SF 8,10,12 }\end{array}$ & 0,01034 & 6.401 .285 & 5.550 .857 & $-13,85$ & $-1,15$ & 115 \\
\hline $\begin{array}{c}\text { Bogor - Manggarai Off } \\
\text { Peak Hour perjalanan } \\
\text { maksimal SF 8,10,12 }\end{array}$ & 0,01034 & 5.237 .415 & 9.832 .058 & 61,22 & 5,10 & 53 \\
\hline $\begin{array}{c}\text { Bogor - Manggarai Peak } \\
\text { Hour perjalanan maksimal } \\
\text { SF 12 }\end{array}$ & 0,01034 & 6.401 .285 & 6.882 .240 & 7,04 & 0,58 & 93 \\
\hline
\end{tabular}




\begin{tabular}{|c|c|c|c|c|c|c|}
\hline $\begin{array}{c}\text { Bogor - Manggarai Off } \\
\begin{array}{c}\text { Peak Hour perjalanan } \\
\text { maksimal SF 12 }\end{array}\end{array}$ & 0,01034 & 5.237 .415 & 12.069 .600 & 81,15 & 6,76 & 43 \\
\hline
\end{tabular}

Lintas Bogor - Manggarai berdasarkan perjalanan saat ini menunjukkan angka kejenuhan -3,44 tahun saat peak hour dan load factor sebesar $153 \%$. Sedangkan perjalanan maksimal berdasarkan perjalanan awal, menunjukkan angka kejenuhan -1,15 tahun saat peak hour dan load foctor sebesar $115 \%$ yang membuktikan bahwa jumlah penumpang akan tetap jenuh pada lintas tersebut apabila perjalanan KRL dimaksimalkan menggunakan stamformasi yang sama. Lintas Bogor - Manggarai berdasarkan perjalanan saat ini menunjukkan angka 2,71 tahun dan load factor sebesar 72 $\%$ saat off peak hour terhitung setelah bulan Desember 2018. Sedangkan perjalanan maksimal berdasarkan perjalanan awal, menunjukkan angka 5,1 tahun saat off peak hour dan load factor sebesar 53\%. Lintas Bogor - Manggarai berdasarkan perjalanan maksimal dengan stamformasi 12 menunjukkan angka kejenuhan 0,58 tahun dan load factor sebesar 93\% saat peak hour. Sedangkan saat off peak hour menunjukkan angka kejenuhan 6,76 tahun dan load factor sebesar $43 \%$ yang membuktikan bahwa masih ada cukup ruang bagi penumpang.

\section{Kesimpulan}

Berdasarkan hasil perhitungan diatas, dapat diambil beberapa kesimpulan sebagai berikut

1. Penumpang di lintas Bogor - Manggarai mengalami pertumbuhan sekitar 1,034\% setiap bulannya. Pertumbuhan jumlah penumpang dapat dibuktikan dengan melihat jumlah penumpang yang selalu meningkat.

2. Headway pada lintas Bogor - Manggarai sebesar 5 menit, dan kapasitas lintas sebanyak 369 perjalanan terbagi menjadi peak hour 134 perjalanan dan off peak hour 235 perjalanan.

3. Lintas Bogor - Manggarai berdasarkan perjalanan saat ini menunjukkan angka kejenuhan -3,44 tahun saat peak hour dan load factor sebesar $153 \%$ yang membuktikan bahwa jumlah penumpang pada bulan Desember 2018 telah melebihi kapasitas angkut lintas berdasarkan kapasitas duduk dan berdiri menggunakan handgrip. Sedangkan perjalanan maksimal berdasarkan perjalanan awal, menunjukkan angka kejenuhan -1,15 tahun saat peak hour dan load foctor sebesar $115 \%$ yang membuktikan bahwa jumlah penumpang akan tetap jenuh pada lintas tersebut apabila perjalanan KRL dimaksimalkan menggunakan stamformasi yang sama.

4. Lintas Bogor - Manggarai berdasarkan perjalanan saat ini menunjukkan angka 2,71 tahun dan load factor sebesar $72 \%$ saat off peak hour terhitung setelah bulan Desember 2018, sehingga dapat diketahui lintas tersebut diperkirakan akan jenuh sekitar bulan September 2021. Sedangkan perjalanan maksimal berdasarkan perjalanan awal, menunjukkan angka 5,1 tahun saat off peak hour dan load factor sebesar 53\%, yang membuat lintas tersebut diperkirakan akan jenuh pada Februari 2024 apabila perjalanan menggunakan stamformasi yang sama.

5. Lintas Bogor - Manggarai berdasarkan perjalanan maksimal dengan stamformasi 12 menunjukkan angka kejenuhan 0,58 tahun dan load factor sebesar 93\% saat peak hour, sehingga lintas tersebut diperkirakan akan mengalami kejenuhan pada bulan Agustus 2019. Sedangkan saat off peak hour menunjukkan angka kejenuhan 6,76 tahun dan load factor sebesar $43 \%$ dapat diperkirakan bahwa lintas tersebut akan jenuh pada Oktober 2025.

\section{DAFTAR PUSTAKA}

Pemerintah Republik Indonesia. (2007). Undang-Undang Republik Indonesia 
Nomor 23. $2007 \quad$ Tentang Perkeretaapian. Jakarta : Presiden Republik Indonesia

Pemerintah Republik Indonesia. (2011) Peraturan Pemerintah Nomor 35. 2011.

Tata Cara dan Standar Pembuatan Grafik Perjalanan Kereta Api. Jakarta: Presiden Republik Indonesia

Pemerintah Republik Indonesia Peraturan Pemerintah Nomor 72. 2009. Lalu Lintas dan Angkutan Kereta Api. Jakarta: Presiden Republik Indonesia

Direktorat Jenderal Perhubungan Darat SK.687/AJ.206/DRJD/2002. Pedoman Teknis Penyelenggaraan Angkutan Umum Di Wilayah Perkotaan Dalam Trayek Tetap Dan Teratur. Direktorat Perhubungan Darat.

PT. Kereta Api Indonesia. Peraturan Dinas 16B Tentang Dinas Kereta Rel Listrik. Bandung

Supriadi, Uned. 2008. Kapasitas Lintas dan Permasalahannya. Bandung

Supriadi, Uned. 2008. Pokok-Pokok Grafik Perjalanan Kereta Api. Bandung

Kamaluddin, Rustian. 2003. Ekonomi Transportasi. Jakarta : Ghalia Indonesia

Akademi Perkeretaapian Indonesia. (2014). Perencanaan Perjalanan kereta Api II. Madiun: Akademi Perkeretaapian Indonesia

Putri, La Reyza Kirana. 2018. Analisis Titik Jenuh Kapasitas Lintas Tanah AbangRangkasbitung Ditinjau Dari Pertumbuhan Jumlah Penumpang. Api Madiun : Madiun

Poerwadarminto, W.J.S. 1976. Kamus Umum bahasa Indonesia. Jakarta: Balai Pustaka.
Hoeve, I. B. V. 1990. Ensiklopedi Indonesia, seri geografi. Jakarta : Intermasa

Mustikarani Wini, Suherdiyanto. 2016. Analisis Faktor-Faktor Penyebab Kemacetan Lalu Lintas Di Sepanjang Jalan H Rais A Rahman (Sui Jawi) Kota Pontianak. Jurnal Edukasi.

Warpani, Swarjoko. (1990). "Merencanakan Sistem Perangkutan". Bandung: Penerbit ITB.

Profillidis, V. A. 2000, Railway Engineering. Ashgate

Timboeleng A. James, Kaseke H. Oscar. 2015. Analisa Biaya Transportasi Angkutan Umum Dalam Kota Manado Akibat Kemacetan Lalu Lintas (Studi Kasus: Angkutan Umum Trayek Pusat Kota 45-Malalayang). Jurnal Sipil Statik.

Association of American Railroads (AAR). 2007. National Rail Freight Infrastructure Capacity and Investment Study. Massachusetts: Cambridge Systematics, Inc

Esveld, C., 2001. Modern Railway Track. MRT Press. The Netherlands

Wiarco Yuwono. 2014. Tinjauan Atas Faktor-Faktor Yang Memengaruhi Kapasitas Jalur Kereta Api. Jurnal Transportasi.

Tamin, Ofyar Z. (2000). Perencanaan dan Pemodelan Transportasi. Bandung: Penerbit ITB.

Anggraini, Devita. 2014. Analisis Faktor Muat Bus Trans Metro Pekanbaru Koridor Terminal Bandar Raya Payung Sekaki- Kulim. Pekanbaru 